\title{
Gente ociosa y malentretenida. \\ Trabajo y pereza en Santafé de Bogotá, siglo XVIII
}

PILAR L ÓPEZ B EJARANO

Bogotá: Universidad de los Andes, Facultad de Ciencias Sociales,

Departamento de Historia

2019 | ISBN 9789587747591 | 321 pp.

DOI: https://doi.org/10.22380/20274688.1465

ANGIE TATIANA PACHECO RODRÍGUEZ

Instituto Colombiano de Antropología e Historia https://orcid.org/0000-0003-4931-1101

C ente ociosa y malentretenida surge de la investigación realizada por la

$\checkmark$ autora en el marco del doctorado en Historia y Civilización de l'Ecole des Hautes Etudes en Sciences Sociales de París, investigación que tiene como objetivo principal comprender "una serie de experiencias históricas frente al trabajo" (xIx) y que se pregunta igualmente por su contrario: la pereza, buscando entender las relaciones en torno a estos dos aspectos en la Santafé del siglo XVIII, a partir de una historia antropológica.

El trabajo se divide en tres partes. La primera de estas, "El proceso colonial y la herencia occidental del trabajo y del no trabajo", constituye un panorama general de la sociedad colonial neogranadina desde el siglo XVI hasta el XVIII, en el que se presentan aspectos que se irán integrando al análisis en los siguientes capítulos, aspectos entre los cuales se encuentran las formas de trabajo indígena (encomienda y mita), los procesos de mestizaje y la jerarquía del color —que influyen particularmente en la diversificación de las formas de trabajo-, así como algunos discursos alrededor de la pereza, lo cual permite entender las 
dinámicas sociales en relación con el trabajo. También se mencionan algunos casos de estudio, como las acusaciones de vagancia y adulterio, que a primera vista parecieran no tener relación con un estudio sobre el trabajo, pero gracias a las cuales la autora puede tanto develar relaciones concretas de trabajo entre los participantes de las querellas como ampliar el espectro de estudio y la mirada sobre estas, trascendiendo un vínculo estrictamente económico. Además, se expone brevemente cómo se transformaron la ideas sobre trabajo y pereza en Occidente desde la Antigüedad hasta mediados del siglo xvinI, y de qué manera tales ideas fueron recibidas en América e influyeron en las leyes y normas promulgadas e impuestas por la Corona española, sobre todo durante la segunda mitad del siglo XviIr. Esto le permite al lector comprender las transformaciones históricas que se dieron alrededor de la idea de lo que es trabajar o no trabajar y cómo se vieron reflejadas en la Santafé del siglo xviı que analiza López Bejarano en los capítulos posteriores.

En la segunda parte, "Vivir y trabajar en Santafé de Bogotá", se presenta un panorama general de la ciudad durante el siglo XVIII, desde su división geográfica hasta los diversos trabajos que se ejercieron en esta ${ }^{\mathrm{I}}$, tomando como fuentes principales una lista de milicias del año I783 y un "censo" del barrio La Nieves, que al parecer es de finales de aquel siglo. Llama la atención el uso del término censo y no el de padrón, que es el tipo de documento analizado por la autora. Censo se entendía como una deuda sujeta a un conjunto de bienes, que debía ser pagada a perpetuidad ${ }^{2}$. Si bien no se trata de un problema complejo, la distinción de estos términos para la época estudiada es importante.

Los documentos en mención permiten ver las actividades desempeñadas por hombres y mujeres (en menor medida) de la ciudad, de manera general, así como algunos ejemplos puntuales del barrio Las Nieves. A partir de ello, la autora clasifica los oficios encontrados de la siguiente manera: los relacionados con la construcción (albañiles y carpinteros), aquellos relacionados con el comercio (pulperos, tenderos, chicherías, revendedores, tratantes y mercaderes) y los que tenían que ver con el vestuario (sastres, costureras y zapateros). El texto se adentra en las diversas relaciones establecidas dentro de tales oficios,

I Debe puntualizarse que el texto no aborda la esclavitud por ser minoritaria en Santafé.

2 Según el Diccionario Lexicográfico de la RAE, el censo se define para I79i como "la cantidad de dinero que recibe el dueño de una hacienda, bienes raíces, oficios, u otros derechos obligándolos al pago de los réditos que en cada año correspondan a la cantidad recibida, la que se llama capital, o principal". Véase: http://ntlle.rae.es/ntlle/SrvltGUIMenuNtlle?cmd=Lema\&sec=ı.o.০.০.০. 
los cuales si bien no parecen haber tenido una organización gremial, sí tenían una jerarquía interna, que puede hacerse obvia, por ejemplo, en el caso de los comerciantes, en la forma de nombrar dicha actividad, en la que además la denominación se daba por una cierta distinción social como el lugar de vivienda ${ }^{3}$ o el tamaño del comercio: a gran o a pequeña escala.

De acuerdo con lo anterior, la autora profundiza en lo que llama "las maneras de trabajar", mostrando cómo el paso de un trabajo obligatorio (particularmente indígena) a uno "libre" (particularmente mestizo) creó otras formas de trabajo, y cómo estas no fueron estáticas ni determinantes para la población de la ciudad; es decir, que una persona no siempre ejercía un único oficio a lo largo de su vida, sino que, por el contrario, podía llevar a cabo actividades paralelas a las declaradas en documentos oficiales como los padrones. En tal escenario, López Bejarano afirma que la "polifonía de maneras de ganarse la vida" pone en evidencia la inestabilidad social de los trabajadores, lo que se puede reafirmar al tener en cuenta que no había una manera clara de pago y, como la autora lo dice: "lo que una persona podía ganar estaba en correlación con el lugar que ocupaba en la jerarquía local” (I37).

Al ver en detalle el papel de dicha jerarquía en las formas de trabajar o no trabajar, aparece la idea de honor, que se vincula en gran medida con el no trabajo de los españoles y criollos, quienes al parecer despreciaban el trabajo "manual", que fue delegado en los indios desde el momento de la conquista y en esclavos y mestizos posteriormente. Sin embargo, durante la segunda mitad del siglo XVIII, los trabajos manuales - como los oficios mencionados - se vinculaban a la idea del "trabajo honesto", una virtud que no necesariamente implicaba el ascenso o reconocimiento social de quienes ejercían dichas actividades. De esta manera, las formas de trabajo se interrelacionaban con la jerarquía del color que la autora menciona en la primera parte del libro, jerarquía que se hace visible en casos como las diferencias entre los sastres del barrio Las Nieves y el sastre del virrey (caso que profundiza en la última parte del libro).

La autora pasa a analizar lo que denomina "los ritmos de vida", capítulo en el que se refiere a una relación más directa con la iglesia — más allá de los valores cristianos alrededor del trabajo-: aquella de la organización del calendario de festividades litúrgicas que se traducían en días de no trabajo. Esos días eran vistos en algunas ocasiones como espacios peligrosos en los que se

3 Dichas denominaciones son: tratantes, pulperos, mieleros, tenderas, revendedores, mercaderes y comerciantes; estos dos últimos son los que vivían en los barrios centrales de la ciudad (II2). 
hacían presentes prácticas como las borracheras y se distraía a los trabajadores de sus labores. Por tal razón, se buscó disminuirlos. A esta altura se hacen más evidentes las ideas relacionadas con prácticas propias de mendigos y vagabundos, cuyas actividades buscaron regular las autoridades coloniales, en especial, entre los artesanos.

De tal manera, se pasa a la tercera parte del libro, titulada "Control y desorden”, en la que se abordan de manera directa las reformas urbanas de la segunda mitad del siglo xvin que pretendieron, entre otros objetivos, regular la vida de los habitantes de la ciudad y que reflejaron el pensamiento "ilustrado" sobre aspectos como la pobreza. Dichas reformas llevaron a la reorganización geográfica y administrativa de la ciudad en cuatro carteles y ocho barrios, con un alcalde cada uno, oficial real que asumía tareas importantes que abarcaban desde la organización de padrones por barrio hasta el control de mendigos, huérfanos y vagos. En este punto cabe preguntarse si tales padrones fueron realmente ejecutados o conservados, ya que esta información, junto con los documentos parroquiales que utiliza la autora, hubiera permitido hacerse un panorama más amplio sobre los oficios ejercidos en la ciudad y ahondar en las relaciones sociales y geográficas de estas, como el caso presentado en el cuarto capítulo sobre el albañil Alonso Morales.

Con relación al control de "vagos y malentretenidos", la autora centra el análisis en la creación de hospicios, espacios dedicados a albergar a estas personas junto con pobres y huérfanos. En tal sentido, analiza el proceso de instalación, las discusiones que ello suscitaba entre religiosos y población civil, y su funcionamiento. Estos aspectos le permiten ver lo que se entendía en ese momento por vagancia, que parece ser más que un grupo determinado de personas, una serie amplia de comportamientos que en el caso femenino se relacionaban con la moral y la sexualidad. Sin embargo, sobre esto último la autora no presenta casos concretos que le permitan ejemplificar la idea de que "el tema recurrente [en las acusaciones de vagancia contra mujeres] era la sujeción y la obediencia a un marido, a un padre, a los jueces, y a los preceptos religiosos, entre otros" (239), lo que hubiera facilitado ahondar en este tema. Empero, esto puede deberse a que, como la misma autora menciona, hubo solamente 44 acusaciones de vagancia entre 1746 y I809, todas relacionadas con sujetos masculinos; es decir, el rastreo de la "vagancia femenina" es más complejo, y podría verse quizás en los intentos de regular las chicherías, que fueron un entorno de trabajo para algunas mujeres durante la Colonia. 
La autora continúa analizando las consecuencias que estas reformas urbanas tuvieron en la Santafé de finales del siglo XVIII e inicios del XIX, como, por ejemplo, la creación de varias normas que buscaban regular el comportamiento ciudadano, a pesar de que algunos oficiales reales se quejaran de que en la práctica tales normas no se cumplían. Igualmente, resalta que en el marco de dicho proceso se creó una "matriz mestiza" que permite entender cómo ciertas ideas acerca del trabajo y la pereza arraigaron a lo largo de la historia de la Nueva Granada y, posteriormente, de la República. De la misma manera, el llamado que se hacía por primera vez en aquel momento a eliminar el estatus de los indígenas como tributarios, podría mostrar cierto proceso de individualización y homogeneización de los trabajadores.

En esta relación se inscribe el relato de Ambrosio López, un sastre que vivió a lo largo de la primera mitad del siglo Xix, relato que muestra cómo en aquel periodo continuó el discurso "moralizador" alrededor del trabajo útil y la vagancia que se implantó a finales del siglo anterior. Sin embargo, vale la pena preguntarse hasta qué punto ese discurso moralizador se transformó en esa primera mitad del siglo xix, y si llegó a adoptar un sentido económico, lo cual, como la autora sostiene, no ocurrió durante el siglo XviII. López Bejarano concluye haciendo un recuento de los temas tratados y proponiendo algunas preguntas que se pueden plantear a partir de su estudio, las cuales llevan a replantearse los lazos establecidos entre la metrópoli y la ciudad de Santafé de Bogotá durante el siglo XviıI, además de las relaciones sociales y económicas internas que se crearon entre los habitantes de esta última.

Finalmente, es necesario señalar que Gente ociosa y malentretenida es un libro que, a diferencia de algunos que se escriben hoy, presenta un trabajo unificado y no una serie de ensayos recopilados bajo un mismo título. Asimismo, la autora hace un amplio uso de fuentes que al parecer carecen de conexión con el estudio del trabajo, lo que le permite ver más allá de relaciones "económicas". Sin embargo, sería interesante contrastarlo con el trabajo esclavo e indígena dentro de la ciudad, que si bien no se aborda en el texto, por ser escaso o relacionado solamente con actividades domésticas (particularmente el indígena), podría ayudar a ampliar la comprensión sobre la diferencia entre trabajo "forzado" y trabajo "libre", además de si las mismas ideas sobre vagancia, vistas entre artesanos y mujeres del pueblo, eran observadas en estos otros grupos. 